\title{
[editorial]
}

\section{Espondiloartritis. ¿Dónde estamos parados en la actualidad?}

\author{
Alberto Berman \\ Profesor de Medicina Interna, Facultad de Medicina, Universidad Nacional de Tucumán. Ex Presidente de la Sociedad Argentina de Reumatología.
}

El estudio de las espondiloartritis en los últimos años ha despertado el interés, generando cada vez más preguntas y necesitando más respuestas.

Clásicamente se agrupa bajo la denominación de espondiloartritis a un conjunto de enfermedades que tienen una serie de características clínicas, serológicas, radiológicas, genéticas, familiares y anatomopatológicas comunes entre sí.

En este ejemplar se publica un trabajo sobre "Manifestaciones reumatológicas y sistémicas en pacientes con

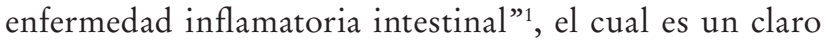
ejemplo de datos obtenidos en nuestro país.

Los nuevos criterios de clasificación del grupo ASAS, clasifica a las Espondiloartritis en Axiales y Periféricas; a su vez, las axiales en radiológicas y no radiológicas. Por otro lado, existen síntomas, signos o síndromes comunes a las diferentes espondiloartritis, entre ellas las artritis reactivas, que pueden presentar hiperqueratosis subungueal, o la balanitis circinada, que histopatológicamente no tiene diferencia con las lesiones histopatológicas de la psoriasis. También, existen pacientes con Artritis psoriásica que presentan úlceras colónicas similares a las de las colitis ulcerosas. Me pregunto, ¿serán estas diferentes "enfermedades" o diferentes expresiones de una misma enfermedad?

Las espondiloartritis indiferenciadas corresponden a aquellos pacientes que no cumplen criterios de clasificación; quizás, ¿estos pacientes podrían estar incluidos dentro de las espondiloartritis axiales no radiológicas? De estos pacientes con espondiloartritis axiales no radiológicas, uno se pregunta si son un estadio temprano o bien se mantendrán como aquellos que no cumplen criterio de Nueva York y que nunca lo cumplirán.

Los criterios de clasificación surgen por la falta de un resultado de laboratorio o marcador que pueda hacer el diagnóstico de certeza de una determinada enfermedad; así es como para cumplir criterios ASAS axial, tenemos un brazo imagenológico y el otro por la presencia del antígeno de histocompatibilidad HLA-B27, o sea nos estamos apoyando en una base genética, de poblaciones caucásicas. En América latina, donde existe una población importante de amerindios y mestizos, la presencia de este antígeno es muy baja; incluso no se encontró Artritis psoriásica en hallazgos arqueológicos en Perú, México y norte de Chile, por lo que uno se pregunta si no estaremos subdiagnosticando pacientes con espondiloartritis por no cumplir criterios de clasificación. Por otro lado, estos criterios han logrado clasificar tempranamente las Espondiloartritis tempranas.

En síntesis, creo que deberíamos clasificar a los pacientes como espondiloartritis axial, periférica o mixta con diferentes expresiones extraarticulares, donde pueda predominar alguna manifestación más que otra.

Por último, sería interesante saber si todos los criterios de clasificación son válidos para todas las poblaciones, ya que sabemos que la predisposición genética también depende de la etnia.

Es necesario e imprescindible producir nuestros propios datos, nuestras estadísticas, nuestros análisis y nuestras conclusiones, a través de base de datos locales como CONAART, CONEART, BIOBADASAR, etc.; ese es el camino, seguir produciendo y construyendo nuestra propia identidad.

\section{Referencia}

1. F.A. Sommerfleck, E.E. Schneeberger, M.A. Suarez Lissi, F. Chiardola, A. Sambuelli, O. Marconi, M.G. Rosemffet, J.A. Maldonado Cocco, G. Citera. Manifestaciones reumatológicas y sistémicas en pacientes con enfermedad inflamatoria intestinal. Rev Arg Reumatol. 2014; 25(2):36-39.

\section{Correspondencia}

E-mail: albertoberman@hotmail.com 